\title{
Advancing treatment, advancing yourself
}

Dental implants are the premier treatment for edentulism, but many practitioners often feel unsure of where to begin. Ucer Education's Postgraduate Certificate (PGCert) in Implant Dentistry (EduQual Level 7), led by Specialist Oral Surgeon, Professor Cemal Ucer, has helped thousands of dentists become proficient in all aspects of implantology.

The multi-system programme will help you to build knowledge in everything from core clinical skill competencies, to getting

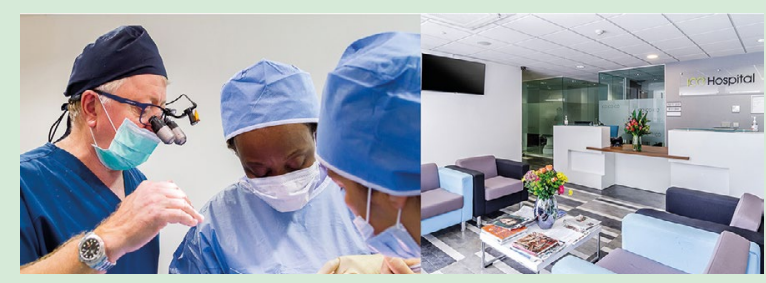

the most out of a fully digital workflow and much more. This course marries the theoretical to the practical, ensuring that by the end of training you will have a broad knowledge of all aspects of modern implant dentistry. It doesn't stop there, though, with on-going support and mentorship available beyond the initial teaching.

If you decide to take your studies further, the course is an excellent step towards an MSc in Implant Dentistry.

For more information on the PG Cert in Implant Dentistry from Ucer Education - supported by Geistlich, Megagen, Neoss, and General Medical - please visit www.ucer.education or contact Prof Ucer on 07767645331 or ucer@oral-implants.com.

\section{Book a test drive today!}

The Axiom Multi Level implant system from Anthogyr provides a highly versatile solution designed to optimise predictability and accessibility of treatment. It contains both tissue level and bone level implants with a singular surgery kit for workflow simplicity.

You can now book an Anthogyr Test Drive to see how the system works in your own hands. The programme includes:
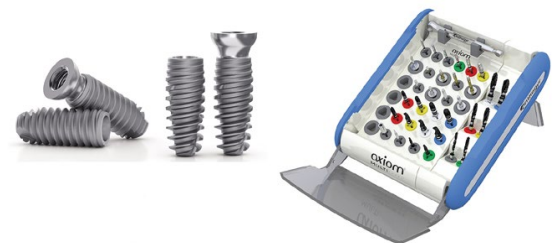

$\rightarrow$ One day use of the Axiom Surgical Kit

$\rightarrow$ One complementary Anthogyr implant

$\rightarrow$ Support from a Territory Manager on the day of surgery

$\rightarrow$ Half price restorative components on selected items.

Available through the Straumann Group, clinicians can have complete confidence in the science behind the Anthogyr implant system and the quality of support provided from a highly knowledgeable and accessible team.

For more information and to book your Anthogyr Test Drive, visit www. anthogyr-uk.co/testdrive.

\section{Introducing the next generation of intraoral scanner}

Innovative. Versatile. Easy-to-use. These are just three ways to describe the new CS 3800 wireless intraoral scanner from Carestream Dental. A system at the very cutting-edge of diagnostic excellence, the CS 3800 wireless features robust and seamless wireless capabilities with up to one hour of continuous scanning. Designed for superior user comfort and functionality, the system can perform a turbo speed scan of a single arch in just 25 seconds.
Plus, the scanner is highly accurate, meaning that professionals can rely on super-quick, crystal clear images every time!

Find out how the CS 3800 wireless can make a difference for you by contacting the team today on 08001699692 or visit www. carestreamdental.co.uk.

.

\section{Game-changing implant surgery}

The award-winning Implantmed surgical unit from W\&H represents 20 years of pioneering research and development. A wide range of technical features and a proven track record make it a true game changer for implant dentists.

To facilitate each stage of implant surgery, the Implanted offers five programmes that can be individually adjusted and stored on the system for ultimate ease-of-use. The unit can also be combined with the W\&H Osstell ISQ module or the Osstell Beacon to accurately measure implant stability, enabling effective management of risk factors for more predictable treatment results. With a multifunctional foot control, the Implantmed is the ideal solution to support your implant surgical workflow. To find out more visit www. wh.com/en_uk, call 01727 874990 or email office.uk@ wh.com.

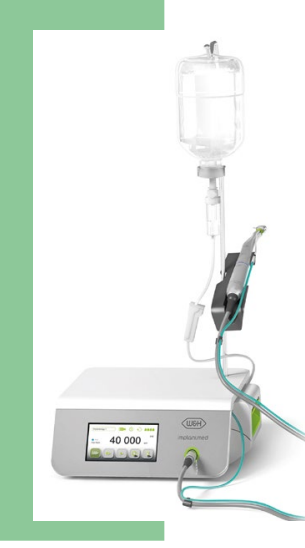

\section{Moisturising protection for your hands}

Many handwashes and hand sanitisers can dry out skin, removing its natural oils and creating dry, cracked areas that could be prone to infection.

Help to protect the hands of your patients and staff with the Steri-7 Xtra hand preparation solution range from Initial Medical, which includes hand rub and wash. These products offer exceptional protection and kill 99.99\% of pathogens including Coronavirus and stay active for up to three hours after application. They offer a high level of hygienic protection to anything from preoperative surgical scrubs to general use in kitchens, washrooms and toilets.

Hand safe and dermatologically tested, the solutions are also moisturising and nourish the hands as they protect, making them the perfect option for repeated use.

For further information visit www. initial.co.uk/medical or call 08708504045 . 